\title{
Mechanical Conditions That Accelerate Intervertebral Disc Degeneration: Overload Versus Immobilization
}

\author{
Ian A. F. Stokes, PhD, and James C. latridis, PhD
}

Study Design. A review of the literature on macromechanical factors that accelerate disc degeneration with particular focus on distinguishing the roles of immobilization and overloading.

Objective. This review examines evidence from the literature in the areas of biomechanics, epidemiology, animal models, and intervertebral disc physiology. The purpose is to examine: 1) what are the degenerationrelated alterations in structural, material, and failure properties in the disc; and 2) evidence in the literature for causal relationships between mechanical loading and alterations in those structural and material properties that constitute disc degeneration.

Summary of Background Data. It is widely assumed that the mechanical environment of the intervertebral disc at least in part determines its rate of degeneration. However, there are two plausible and contrasting theories as to the mechanical conditions that promote degeneration: 1) mechanical overload; and 2) reduced motion and loading.

Results. There are a greater number of studies addressing the "wear and tear" theory than the immobilization theory. Evidence is accumulating to support the notion that there is a "safe window" of tissue mechanical conditions in which the discs remain healthy.

Conclusions. It is concluded that probably any abnormal loading conditions (including overload and immobilization) can produce tissue trauma and/or adaptive changes that may result in disc degeneration. Adverse mechanical conditions can be due to external forces, or may result from impaired neuromuscular control of the paraspinal and abdominal muscles. Future studies will need to evaluate additional unquantified interactions between biomechanics and factors such as genetics and behavioral responses to pain and disability.

Key words: intervertebral disc, degeneration, biomechanics, immobilization, microfailure. Spine 2004;29: 2724-2732

It is thought that the mechanical environment of the intervertebral disc can predispose to disc degeneration and associated painful symptoms. Disc degeneration appears to be an inevitable consequence of aging, with specific and substantial alterations occurring in the structural,

From the Department of Orthopaedics and Rehabilitation and the Department of Mechanical Engineering, University of Vermont, Burlington, Vermont.

Supported by research grants from the NIH (R01 AR 049370 and K01 AR 02078) and by The Whitaker Foundation.

The manuscript submitted does not contain information about medical device(s)/drug(s).

Federal funds were received to support this work. No benefits in any form have been or will be received from a commercial party related directly or indirectly to the subject of this manuscript.

Address correspondence to James C. Iatridis, 231B Votey Building, Department of Mechanical Engineering, University of Vermont, Burlington, VT 05405; E-mail: james.iatridis@uvm.edu material, and failure properties of the disc over time. Despite this, aging and degeneration may involve separate processes, and there is wide variability in the extent to which the degenerative changes become painful and symptomatic. This paper examines the evidence concerning the relationship between mechanical environment and changes in the mechanical properties of the disc and its tissues as they relate to the pathogenesis of disc degeneration. In other words, what aspects of the mechanical environment of the disc accelerate degeneration, and what kind of mechanical environment inhibits degeneration? In particular, what are the relative roles of overloading and immobilization (or hypomobility) on the intervertebral disc?

In the context of this review, the two contrasting mechanical conditions (overload and immobilization) are terms used to imply alterations in both motion and loading. Intervertebral motion produces tissue strains, as does loading. An excessive range of motion will induce large strains of at least some of the spinal tissues. The converse may not necessarily be true, because lesser motion may not be a result of reduced loading. This review also concentrates on the macroscopic scale, although it is not possible to separate spinal behavior at this scale from the events at the cellular level.

\section{- Competing Hypotheses Concerning Which Mechanical Environments Accelerate Disc Degeneration}

In the overload, or "wear and tear," hypothesis, it is proposed that a demanding mechanical environment produces localized trauma of the disc that will be slow to heal because of the slow turnover of disc tissue. ${ }^{1}$ Thus, the accumulation of tissue injury and "microtrauma" progressively weaken the disc, making it more susceptible to further injury (Figure 1). In this way, mechanical injuries weaken the disc, increasing the risk of further injury, and a vicious cycle of accumulating injury that outstrips the disc's capability for biologic repair develops. ${ }^{2,3}$

In a contrasting hypothesis for the mechanical pathogenesis of disc degeneration, it is suggested that hypomobility of the disc produces adaptive changes that may cause tissue weakness and degeneration, subsequent pain, and further reduced motion, again in a vicious cycle as was proposed for the case of articular cartilage. ${ }^{4}$ Within this hypothesis, there are differing explanations for the mechanisms of tissue weakening: hypomobility could produce altered (reduced) stimulus to the metabolic activity of disc cells (as reviewed by Setton in this issue of Spine) or altered transport of nutrients and metabolites (as reviewed by Urban in this issue of Spine). A 


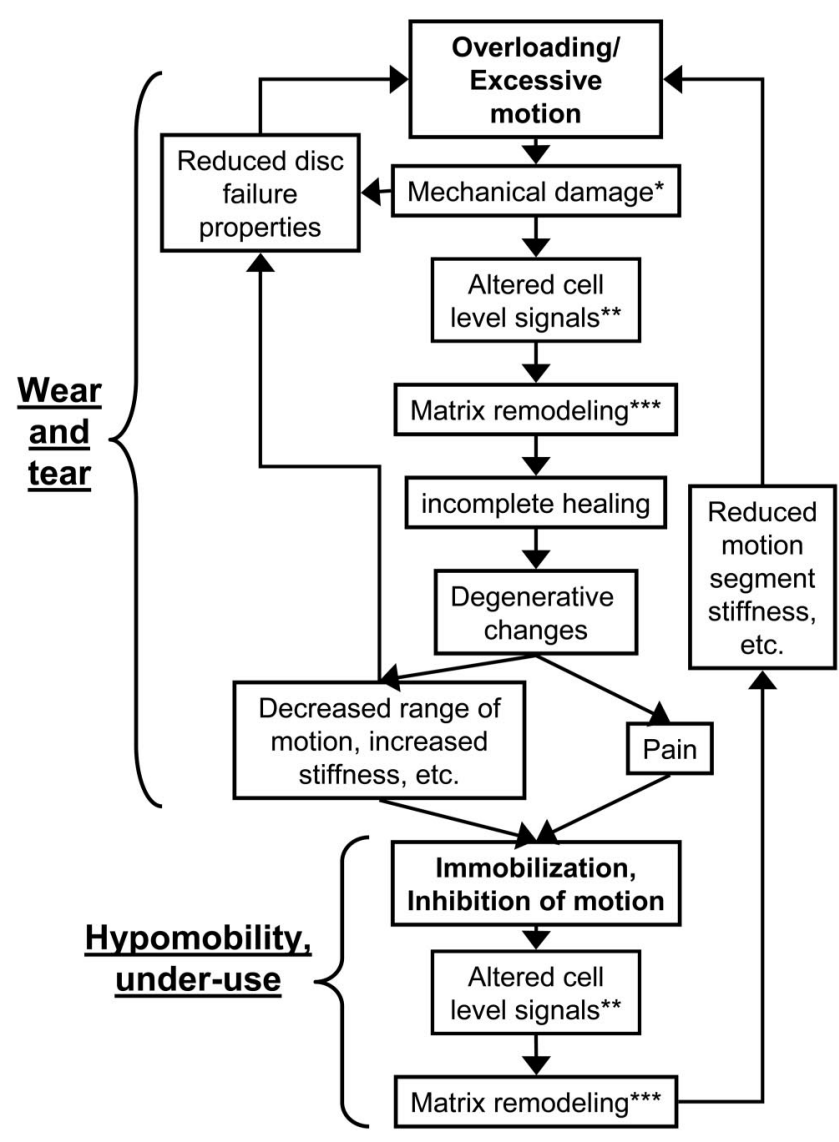

Figure 1. A diagram of some supposed biomechanical interactions that can produce disc damage and degeneration. In the early stages of disc damage, a "wear and tear" mechanism applies, and the small lesions are probably not painful. More advanced and more painful degenerative changes encourage hypomobility and underuse, which in turn may accelerate degeneration. *Mechanical damage to the disc can include fiber damage, delamination, anulus tears, and associated proteoglycan loss. ${ }^{* *}$ Altered cell level signals can include fluid flow, cell strain, altered nutrition, accumulation of waste products, and loss of cellularity. ${ }^{* * *}$ Matrix remodeling can include alterations in gene expression, enzyme activity, composition, and structure.

further confounding factor may be the calcification of the endplate ${ }^{5}$ and impairment of that major pathway for diffusive and convective transport, which may also be affected by mechanical loading conditions. Although the immobilization model for degeneration of articular cartilage has been clearly demonstrated, ${ }^{6-11}$ it has not been proven in the human spine. There are both similarities and differences between intervertebral discs and synovial joints: the stress magnitudes in disc tissue have been estimated to be approximately 0.1 to $0.3 \mathrm{MPa}$ under low loading conditions with values as high as 1 to $3 \mathrm{MPa}$ under more extreme loading conditions ${ }^{12-15}$ and about a factor of 10 lower than the contact stress calculated between cartilage layers in diarthrodial joints. However, both tissues are avascular and depend on tenuous nutritional pathways. Articular cartilage is susceptible to consequences of synovial inflammation that are absent in the disc.

Both the overload and hypomobility mechanisms may occur in the early and later stages of degeneration, re- spectively. It has been suggested that a degenerative cascade occurs with initially increased flexibility and hypermobility in early disc degeneration that results in painful limitation of motion and eventually by tissue stiffening and hypomobility. ${ }^{16}$

The purpose of this review is to examine: 1) what are the degeneration-related alterations in structural, material, and failure properties in the disc; and 2) the evidence in the literature for causal relationships between mechanical loading and alterations in structural and material properties that constitute disc degeneration.

\section{Epidemiology: Is Disc Degeneration (and Associated Pain) Associated With a Particular Lifestyle?}

Although back pain itself has been associated epidemiologically (as reviewed by Videman and Nurminen in this issue of Spine) with occupations that involve repetitive loading, vibration (e.g., truck driving), and acute overload of the spine, ${ }^{17}$ the evidence for the underlying pathomechanisms is mostly indirect. The development of lumbar disc rupture is associated with frequent bending and twisting, ${ }^{18}$ fatigue loading, ${ }^{19}$ heavy physical work,${ }^{20}$ and a sedentary environment that implies hypomobility, but may also contribute to increased intradiscal pressure in the seated posture. ${ }^{21}$ Because many epidemiological studies use self-reported back pain or working days lost as a measure of effect, the exact contribution to disc degeneration (as opposed to painful symptoms) is not clear. For instance, occupational driving is associated with pain, ${ }^{17}$ but not with magnetic resonance imaging (MRI) evidence of disc degeneration. ${ }^{22}$ Evidence based on $\mathrm{MRI}^{23}$ suggests that occupation makes a small contribution to the degeneration of the disc. However, the correlation between MR changes and painful symptoms is tenuous. ${ }^{24,25}$ Similarly, findings of disc herniation and degenerative changes by computed tomography (CT) scans have a very high prevalence in asymptomatic individuals. $^{26}$

\section{- In Vivo Motion and Loading Changes in Persons With Low Back Pain}

Investigations on persons with low back pain have demonstrated reduced intervertebral motions in patients as compared to controls as well as alterations in the coupled patterns of motion. ${ }^{27-31}$ Patients with low back pain also demonstrated alterations in muscular activation patterns ${ }^{32-34}$ that can result in increased axial compression and shear loading on the spine. ${ }^{35}$ It is difficult to identify the causes of these reported functional alterations, because they may also be a consequence of pain.

\section{- Neuromuscular Control of the Spine}

The spine is loaded in vivo by external forces and internal forces generated by muscles. In general, the muscular forces and consequential forces acting on the spine are larger than the external forces, because of the smaller moment arms of the muscles. Because the muscles are more numerous than the number of degrees of freedom 
of the spine that they control, each trunk loading condition can be associated with an indeterminate number of muscle activation patterns, each involving differing loads on the discs. Thus, there is no direct relationship between a task and the spinal loading-it depends on the individual and the individual circumstances. Coactivation of antagonistic muscles is apparently a strategy that increases trunk stability, but at the expense of added spinal loading. ${ }^{36-38}$ Increased spinal loading increases the segmental stiffness, ${ }^{39-43}$ and the additional stiffness can be a factor in increasing the stability of the spine. ${ }^{43}$

Low back pain (LBP) is thought to be associated with altered muscle recruitment patterns, either as a predisposing cause of the pain or as a secondary response to pain. Three general aspects of altered muscle recruitment patterns in people with back pain have been investigated: 1) altered muscle activation patterns, especially coactivation, in a static task such as pulling against a fixed object or slow lifting; 2) altered muscle reflex latency times in response to a sudden perturbation such as a dropped weight, quick release of trunk loading, or moving support platform; and 3) altered muscle activation pattern in anticipation of an unexpected or voluntary perturbation.

The literature review by van Dieën $e t$ al ${ }^{44}$ examined reports of trunk muscle activation with respect to two alternate hypotheses as to possible differences between patients with and without back pain. In the "painspasm-pain" hypothesis, it is proposed that a vicious cycle of hyperactivated muscles and pain develops, with the individual consciously or unconsciously "splinting" against painful motion. In the "pain adaptation" hypothesis, it is proposed that there is increased antagonistic activation of muscles that slows motion and hence guards against the exacerbation of existing pain. Their review indicated that the available data did not consistently support either hypothesis, and, as an alternative, the authors proposed that the observed differences were consistent with the notion that persons with back pain adopt strategies that enhance the stability of the spine.

\section{- Spinal Stability}

Spinal instability is a term that has been used ambiguously to refer to intervertebral hypermobility, an altered pattern of intervertebral coupled motion, a variable pattern of painful symptoms, or frank buckling of the spinal column. ${ }^{45}$ It is possible that sudden buckling of the spine is responsible for some sudden onset episodes of low back pain. Because the spine is inherently unstable, it must be stabilized by a combination of muscular and spinal stiffness. ${ }^{43}$ In this supposed mechanism, spinal buckling causes large localized tissue deformations and associated painful tissue damage. Buckling instability cannot be induced experimentally in living patients, so it must be studied indirectly. For instance, after a perturbation, the amount of subsequent trunk excursion and/or the magnitude and timing of muscular response to a perturbation can be recorded. Persons with LBP might respond differently to the anticipation of the perturbation or the actual perturbation. Two possible altered muscle activation strategies can be proposed: in the first, individuals with LBP would preactivate muscles to stiffen the trunk in anticipation (apprehension) of the perturbation, but at the cost of greater muscle forces and spinal loads, that might themselves be painful. In the second mechanism, they might be more likely to respond or possibly overactivate muscles following a perturbation, because they would be apprehensive of possibly large and painful tissue deformations.

\section{- Changes in the Mechanical Properties of the Spine as Correlated With Age and Degeneration}

\section{Motion Segments}

In early stages of degeneration, the axial momentrotation properties of the motion segment demonstrate some increases in range of motion, which are followed, in advanced degeneration, by some reduced range of motion and a tendency for the region of laxity around the "neutral position" to increase. ${ }^{46}$ These findings are consistent with concepts of overload and hypomobility at early and later stages of degeneration, respectively. ${ }^{16}$ Flexion-extension and lateral bending, on the other hand, demonstrate a monotonic decrease in range of motion with the progression of degeneration. ${ }^{46}$ These changes in the mechanical behavior may result from a combination of arthritic changes in the facet joints and subchondral sclerosis, though apparently independent of the presence of osteophytes. ${ }^{47}$ However, the amount of variability between individual motion segments is large compared to the differences associated with degeneration. ${ }^{48}$

In reality, the load displacement relationships in the intervertebral motion segments are highly complex and include six interrelated degrees of freedom, timedependent behavior, and structural and material nonlinearity. These aspects may each be affected differently by degeneration. It has been proposed ${ }^{49}$ that a region of laxity near the neutral position of a motion segment (the "neutral zone") is most affected by degeneration and that this can lead to painful motion. The functional range of motion depends on spinal flexibility as well as the motion that is permitted by muscular control. Thus, although degeneration has been associated with motion segment hypermobility, pain is thought to restrict in vivo motion. However, many asymptomatic individuals also have a small in vivo range of spinal motion in the range considered to represent spinal impairment. ${ }^{50}$ Trunk flexibility (i.e., voluntary range of motion) is apparently not predictive of subsequent back pain. ${ }^{51}$

\section{Intervertebral Disc}

Degeneration and age-related changes in both the biochemical composition and structure of the anulus and nucleus of the intervertebral disc have been reported. ${ }^{52-56}$ As discs degenerate, the nucleus becomes more consolidated and fibrous and is less clearly demarcated 
from the anulus fibrosus. Focal defects appear in the cartilage endplate, and there is a decrease in the number of layers of the anulus with an increase in the thickness and spacing of the collagen fibers. ${ }^{57-59}$ Degeneration is associated with decreased hydration, especially in the nucleus. ${ }^{52}$ Water content in the nucleus pulposus drops from about $90 \%$ of the tissue wet weight in the infant to less than $70 \%$ in the elderly. In the anulus fibrosus, the water content remains relatively constant with age and is approximately $60 \%$ to $70 \%$ of the tissue's wet weight.

As a consequence of these degeneration-related alterations in structure and composition (as reviewed by Roughley et al in this issue of Spine) of disc tissues, changes occur in material and structural properties of the component parts of the disc. The shear modulus of the nucleus increases 8 -fold with degeneration and the decrease in relative energy dissipation suggests that the nucleus pulposus undergoes a transition from fluid-like to solid-like behavior with aging and degeneration. ${ }^{60}$ In the anulus fibrosus, there is a significant increase in compressive modulus ${ }^{61}$ and decrease in radial permeability, ${ }^{62}$ as well as a moderate increase in shear modulus ${ }^{63}$ of the tissue with grade of disc degeneration. These alterations may be explained by the loss of water content and increase in tissue density. Increases in the axial and circumferential permeability ${ }^{62}$ as well as alterations in the Poisson ratio ${ }^{64}$ with degeneration are probably related to structural remodeling and perhaps microfailure resulting from the degenerative process. Alterations in the streaming potential response of anulus tissue with degeneration provide further evidence of the relationship between tissue fixed charge density, water content, and material properties. ${ }^{65}$ These degeneration-related changes in material properties also correlate with age, making a distinction difficult because these two processes frequently occur in parallel. Separating these two effects may be a key step in understanding the process of disc degeneration.

These compositional and structural changes in turn alter the macroscopic behaviors as seen in the disc flexibility $^{46}$ and intradiscal pressure. ${ }^{12,66-68}$ Injurious joint loading conditions have mechanical consequences including fiber microfracture or macroscopic tissue failure.

Failure in Intervertebral Discs in Response to Loading Evidence from in vitro motion segment testing including mechanical injury and fatigue experiments indicates that the disc can undergo tissue damage consistent with the formation of anular tears especially after sustained loading $^{69}$ and repetitive (fatiguing) loading ${ }^{19}$ intended to simulate a strenuous day's activity. The relative contributions of the anulus, nucleus, and posterior elements can be substantially altered by fluid shifts associated with sustained loading and by degenerative changes. ${ }^{66,70}$

In vitro, lumbar disc rupture has been simulated through loading of the motion segment with hyperflexion and twisting and with fatigue loading. ${ }^{19,71,72}$ In fatigue loading, relatively modest magnitudes of repetitive flexion and extension as well as compression (to a lesser extent) caused disc herniations in porcine spine motion segments. $^{73}$

Because the anulus can be considered to be a composite material, it is resistant to complete failure. The laminated structure of this kind of composite material requires multiple cracks and microfailure to occur (i.e., matrix cracking, delaminations, and fiber failure) before final failure of the whole tissue. The anulus tissue can be damaged by a combination of fiber rupture and separation of layers (delamination). An evaluation of damage mechanisms in the disc anulus indicated that delaminations in the anulus are likely implicated in damage propagation, whereas fiber breaks were assumed to be a likely failure mode only under extreme loading conditions or when collagen damage occurs over a reasonably large region. ${ }^{74}$ Delaminations have been reported as failure mechanisms for isolated anulus fibrosus specimens, ${ }^{75}$ and separation of layers has been demonstrated in the anulus of intact motion segments. ${ }^{19,76,77}$ Delamination occurs in the presence of high interlaminar shear stresses that in turn are increased after initial radial and circumferential tears in the anulus. ${ }^{78}$ The decrease in the number of layers and increase in the thickness of each layer that occurs with degeneration and aging ${ }^{58}$ also directly increases the interlaminar shear stresses. ${ }^{74}$

In studies of anatomic specimens, the presence of tears in the anulus fibrosus increases rotational (especially axial rotational) flexibility of lumbar motion segments ${ }^{79}$ and is associated with disc degeneration. ${ }^{80}$

A computational simulation of the disc degeneration process indicated that failure occurred initially at the endplates before anulus rupture and failure propagation. ${ }^{81}$ Failure at the endplate, such as a rim lesion, may initiate a stress free region or edge, thereby creating interlaminar shear stresses resulting in delamination and the initiation or propagation of failure in the anulus. ${ }^{74,78}$

It is likely that mechanically induced remodeling leads, at least in part, to a causal relationship between altered kinematics and microfailure or macrofailure in the disc tissue leading to a degenerative cascade (Figure 1). Although the pathologic processes or the micromechanical disorders that give rise to disc degeneration and low back pain remain obscure, ${ }^{82}$ epidemiological studies point to a relationship. Physically fit people have a decreased incidence of low back pain, whereas sedentary posture is associated with back pain. ${ }^{20,82}$ Development of lumbar disc rupture is associated with activities generating higher disc stresses, including frequent bending and twisting, heavy physical work, ${ }^{20}$ and exposure to vibration. ${ }^{83}$ Two specific human conditions-spinal fusion and scoliosis-in which spinal loading is thought to be altered provide some insights into the possible link between mechanical environment and disc degeneration.

\section{Clinical Evidence of Disc Degeneration in Fused Segments and Segments Adjacent to a Fusion}

The apparently iatrogenic acceleration of degeneration in motion segments that are adjacent to a surgical arth- 
rodesis (fusion) is often attributed to altered mechanics in the spinal column. The adjacent segments are assumed to experience altered biomechanical conditions, including increased intervertebral motion, facet loads, tissue stresses, and intradiscal pressure, which are affected by the length, location, and stiffness of the fusion mass ${ }^{84-91}$ supporting the overloading hypothesis. A decrease in the aggregating capacity of proteoglycans in the intervertebral disc, as well as a decrease in proteoglycan content in the nucleus, was reported at the fused level in a dog model. ${ }^{92}$ The authors further suggested that the biochemical differences at the fused levels were larger than those at adjacent segments but of similar nature. ${ }^{92}$

Although a remodeling phenomenon is demonstrated in this animal model and may be at least partly responsible for a "degenerative cascade," it is impossible to separate the concurrent degenerative disease processes from biomechanically induced changes in the case of human spinal fusion. This relationship is even less clear when symptomatic outcomes are considered, as adjacent segment degeneration may not produce clinical symptoms. ${ }^{93-96}$ It has also been suggested that individual characteristics such as genetics and psychosocial characteristics are more important than fusion length in predicting clinical outcome. ${ }^{97,98}$

\section{Disc Degeneration and Scoliosis}

In human scoliosis, disc composition and ratio of type I to type II collagen is altered, with the total collagen concentration and ratio of type I to type II collagen being greatest on the concave side of the curve. ${ }^{99}$ An elevated protein synthesis activity has also been observed in the convex side of scoliotic discs compared to the unaffected tissue. ${ }^{100}$ These changes were attributed to altered mechanical environments in an expression of the Wolff Law. Other studies on scoliotic intervertebral discs further suggest that mechanical loading conditions lead to remodeling of the matrix proteoglycan content and structure, as well as expression of type X collagen. ${ }^{101-104}$

In scoliotic discs removed at surgery, differences in cell viability correlated with changes in nutrient and metabolite levels and also with disc deformity (convex versus concave side, and distance from curve apex). ${ }^{105}$ However, no loss of matrix macromolecules was seen in these studies. This was likely because the period between cell death and surgery was short compared to the long matrix turnover times. Intraoperatively (when the muscular loading of the spine was minimal), it was reported by Urban et al $^{106}$ that solute diffusion into the apical disc (measured by flux of nitrous oxide) was reduced. This could be due to abnormal mechanical stress on the disc or increased endplate calcification limiting solute diffusion. ${ }^{106}$ The authors speculated that asymmetrical loads, tissue deformation, and nutrient supply may work separately or in combination to cause cell death within the disc. It appears that in scoliosis, there is a combination of overload and reduced motion that results in reported remodeling changes in composition and structure.

\section{Alterations in Mechanical Loading in Animal Models and Tissue Culture}

Numerous mechanical interventions to the disc in vivo have been shown to result in structural and compositional changes to the disc in animal models. ${ }^{107}$ For example, in dogs, long distance running was shown to influence the proteoglycan content in the intervertebral discs, with reductions in the cervical and thoracic levels, but increases in the lumbar discs. ${ }^{108}$ Compositional differences with spinal level were attributed to distinct biomechanical demands, suggesting that the type of mechanical forces, loading frequency, and duration all influence composition. Sustained superphysiological static compression on dog lumbar discs resulted in alterations in proteoglycan and collagen content and structure with no obvious signs of degeneration. ${ }^{109,110}$

A number of animal models involving disc injury are reported, but here it is difficult to identify the contribution of alterations in mechanical environment of the tissue. ${ }^{40,111,112}$ The intended intervention may be confounded by reparative effects; for instance, in the Sullivan et al model, ${ }^{113}$ in which facet joints are removed from the rabbit lumbar spine with the intention of producing hypermobility, it was reported ${ }^{114}$ that a rapid formation (in a few weeks) of scar tissue resulted in the flexibility of the spine returning to preintervention values.

Mechanical interventions in vivo are more easily achieved in the tail than the spine, allowing more precise mechanical control over the joint loading conditions. Application of static loads on the order of $1 \mathrm{MPa}$ have been shown to induce cell apoptosis and altered structural properties (disc thickness, axial compliance, and angular laxity), matrix content (proteoglycan and type I and II collagen), metalloproteinase activity, and disc cell gene expression (aggrecan and collagen II). ${ }^{115-119}$ This sustained axial compression resulted in a loss of disc height, altered disc stiffness, loss of water content, increased collagen fiber content in the nucleus, and cellular apoptosis with clear signs of degenerative changes. Historically, chronic load studies have focused on static compression applied 24 hours/day for 1 to 53 weeks. ${ }^{109,110,115-118}$ In a study that attempted to isolate immobilization from compression, a separate immobilization group of animals was used. Immobilization produced remodeling changes that were similar to static compression with lesser alterations in structure and composition. ${ }^{116}$ It is important to note, however, that 24 hours of static loading per day is not a physiologic loading condition, and even with separate immobilization groups, it is difficult or impossible to separate the effects of immobilization from altered loading. The tail models have also been criticized based on differences in loading (though not necessarily stress differences) between tail discs and spinal discs, and some differences in structural properties have been reported between discs of the tail and lumbar spine. ${ }^{120}$

Recent device development has allowed investigation of the separate effects of immobilization and overloading in the in vivo tail models under dynamic conditions. It was demonstrated that dynamic compression results in 
detectable alterations in gene expression and histochemistry within very short times (i.e., 2 hours to 1 week). ${ }^{121,122}$ Notably, there was a threshold in both magnitude $(\sim 0.2 \mathrm{MPa})$ and frequency $(\sim 0.2 \mathrm{~Hz})$ needed to maintain homeostasis in the disc. ${ }^{123}$ Also, dropping below this threshold with immobilization loading resulted in a down-regulation of anabolic gene expression, whereas dynamic compression following immobilization resulted in a partial recovery of this down-regulation. ${ }^{121}$ Loading above this threshold with high compression magnitudes at either a high $(1 \mathrm{~Hz})$ or low frequency caused disc cells to respond by altering mRNA production. ${ }^{123}$ This frequency threshold with dynamic compression loading was also reported for rat tail disc mechanical behaviors where daily 1-hour loadings at 0.7 $\mathrm{MPa}$ and $1.5 \mathrm{~Hz}$ for 17 days resulted in disc structural properties that were closest to the sham group with static compression and dynamic compression at $0.5 \mathrm{~Hz}$ and $2.5 \mathrm{~Hz}$, resulting in more substantial alterations in structural properties. ${ }^{124}$

The idea that activity increases the transport of nutrients and metabolites in the disc was investigated by Urban et al. ${ }^{125}$ They reported that radioisotopes in the blood of exercising dogs were not transported into the disc at a rate faster than that expected by diffusion, suggesting that essential nutrients are transported through diffusion. However, they calculated that a "pumping" effect would augment transport of molecules larger than the sulfate ions in their experiments.

\section{- Mechanisms of Adaptive Changes in the Intervertebral Disc}

Mechanically induced disc degeneration apparently occurs in two related pathways. ${ }^{64}$ The first suggested pathway is that certain loading conditions directly damage the intervertebral disc, e.g., hyperflexion ${ }^{72,81,90}$ The second (indirect mechanism) is that alterations in the material properties of disc subcomponents from damage or remodeling may weaken the disc. For example, mechanical stimuli may lead to loss of swelling pressure of the nucleus or decreased failure strength of the anulus fibrosus. ${ }^{60,61,63,64,126}$

Although evidence on the metabolic responses of the disc to mechanical environment is being accumulated from cell, tissue, and organ culture studies, it remains difficult to identify the relationship between loading and degeneration at the macroscopic level. In cell and tissue culture, changes in hydrostatic pressure and osmotic pressure have been found to alter gene expression (TIMP-1, matrix metalloproteinase [MMP-3], types I and II collagen, aggrecan) and synthesis rates of extracellular matrix proteins (35S-sulfate and $3 \mathrm{H}$-proline incorporation $)^{127-131}$ in a dose-dependent and regionspecific manner. It is interesting that static hydrostatic pressure applied to pieces of bovine discs for only 20 seconds (followed by 2 hours of recovery) tended to stimulate proteoglycan synthesis at low magnitudes (1-7.5 $\mathrm{MPa}$ ), whereas 2 hours of loading resulted in an increase in synthesis only at $5 \mathrm{MPa}$ and a decrease at higher loads $(7.5-10 \mathrm{MPa}){ }^{131}$ Although it is very clear that intervertebral disc cells are quite sensitive to mechanical stimuli, the relationship between the joint loads applied to the intervertebral disc and its biologic response is not well understood.

Studies on the intervertebral disc tissue in vitro have attempted to isolate the precise biosynthetic response to applied mechanical loading. Compressive forces, ${ }^{132}$ vibration, ${ }^{133}$ and pressurization ${ }^{127,128,130,131}$ stimulate proteoglycan and collagen production, yet at high magnitudes can inhibit protein production. The specific mechanical signals on disc cells include pressure, stress, and strain and can be evaluated with combined experimental and computational approaches. ${ }^{134}$ These topics are addressed further in the review by Setton and Chen in this issue of Spine.

\section{- Conclusions Concerning Possible Mechanisms of Mechanically Accelerated Disc Degeneration}

Evidence is accumulating to support the notion that there is a "safe window" of tissue mechanical conditions in which the discs remain healthy. Outside this range, overloading of the tissues produces localized injury that is slow to be repaired; conversely, a mechanical environment that is deprived of motion and other mechanical stimulus impairs the maintenance of tissue homeostasis. Thus, both situations can lead to disc degeneration. Muscular forces form the largest contribution to spinal loading under most circumstances, so differing neuromuscular control may help to explain why some individuals are more susceptible to degeneration that is secondary to inappropriate mechanical loading. Because both immobilization and overloading are implicated in remodeling of the disc, it is likely that both can contribute to progressive degeneration. However, it appears that more studies have been directed at documenting the effects of "wear and tear" and overload than the effects of underuse and immobilization. In vivo studies of patients with LBP demonstrate reduced intervertebral motion and increases in compression and shear loading on the spine in certain activities. In vivo animal models with controlled compression loading have documented the effects of immobilization and overloading separately and show that there is a threshold of mechanical loading required for maintaining normal ("healthy") disc composition, structure, and mechanical properties. Immobilization leads to reduced protein synthesis that may result from a lack of mechanical stimulus (or stimulus below a certain threshold) or lack of nutritional supply. On the other hand, according to animal studies, high magnitudes and high frequencies of dynamic and static compression produce cell apoptosis, increased catabolic gene expression and enzymatic activity, and altered structural properties.

The causal relationship between mechanical loading and degenerative changes in the human spine are less 
clear. It is likely, however, that disc remodeling in response to immobilization or overload may result in altered (and perhaps deteriorated) material properties and changes in structure, and this may predispose the disc to failure on the microstructural or macrostructural level. However, mechanical studies on the tissue level and motion segment level also indicate that disc ruptures and their progression in a "degenerative cascade" can only occur when overloading is also involved.

\section{- Key Points}

- The majority of studies on mechanical involvement in disc degeneration focus on the "wear and tear theory" and not on the influence of underuse and immobilization.

- Mechanical studies on the tissue level and motion segment level indicate that disc ruptures and their progression in a "degenerative cascade" can only occur when overloading is also involved.

- Both immobilization and overloading are implicated in remodeling of the disc. Overloading of the tissues produces localized injury that is slow to be repaired, whereas a mechanical environment that is deprived of motion and other mechanical stimuli also impairs the maintenance of tissue homeostasis.

\section{References}

1. Urban JP, Roberts S. Development and degeneration of the intervertebral discs. Mol Med Today 1995;1:329-35.

2. Adams MA, Burton K, Bogduk N, et al. Biomechanics of Back Pain. New York, NY: Churchill Livingstone; 2002.

3. Adams MA, Freeman BJ, Morrison HP, et al. Mechanical initiation of intervertebral disc degeneration. Spine 2000;25:1625-36.

4. Videman T. Connective tissue and immobilization. Key factors in musculoskeletal degeneration? Clin Orthop 1987:26-32.

5. Roberts S, Urban JP, Evans H, et al. Transport properties of the human cartilage endplate in relation to its composition and calcification. Spine 1996;21:415-20.

6. Hong SP, Henderson CN. Articular cartilage surface changes following immobilization of the rat knee joint. A semiquantitative scanning electronmicroscopic study. Acta Anat (Basel) 1996;157:27-40.

7. Leroux MA, Cheung HS, Bau JL, et al. Altered mechanics and histomorphometry of canine tibial cartilage following joint immobilization. Osteoarthritis Cartilage 2001;9:633-40.

8. Muller FJ, Setton LA, Manicourt DH, et al. Centrifugal and biochemical comparison of proteoglycan aggregates from articular cartilage in experimental joint disuse and joint instability. J Orthop Res 1994;12:498-508.

9. Narmoneva DA, Cheung HS, Wang JY, et al. Altered swelling behavior of femoral cartilage following joint immobilization in a canine model. $J \mathrm{O} r$ thop Res 2002;20:83-91.

10. Saamanen AM, Tammi M, Jurvelin J, et al. Proteoglycan alterations following immobilization and remobilization in the articular cartilage of young canine knee (stifle) joint. J Orthop Res 1990;8:863-73.

11. Setton LA, Mow VC, Muller FJ, et al. Mechanical behavior and biochemical composition of canine knee cartilage following periods of joint disuse and disuse with remobilization. Osteoarthritis Cartilage 1997;5:1-16.

12. McNally DS, Adams MA. Internal intervertebral disc mechanics as revealed by stress profilometry. Spine 1992;17:66-73.

13. Nachemson AL, Morris JM. In vivo measurement of intradiscal pressure. J Bone Joint Surg Am 1964;46A:1077-92.

14. Ranu HS. Measurement of pressures in the nucleus and within the annulus of the human spinal disc: due to extreme loading. Proc Inst Mech Eng 1990;204:141-6.

15. Wilke H, Neef P, Hinz B, et al. Intradiscal pressure together with anthro- pometric data-a data set for the validation of models. Clin Biomech (Bristol, Avon) 2001;16(suppl 1):S111-26.

16. Yong-Hing K, Kirkaldy-Willis WH. The pathophysiology of degenerative disease of the lumbar spine. Orthop Clin North Am 1983;14:491-504.

17. Kelsey JL, White AA 3rd. Epidemiology and impact of low-back pain. Spine 1980;5:133-42.

18. Farfan HF. The torsional injury of the lumbar spine. Spine 1984;9:53.

19. Adams MA, Hutton WC. The effect of fatigue on the lumbar intervertebral disc. J Bone Joint Surg Br 1983;65:199-203.

20. Frymoyer JW. Epidemiology. In: Frymoyer JW, Gordon SL eds. New Perspectives in Low Back Pain. Park Ridge, IL: American Academy of Orthopaedic Surgeons; 1989;19-34.

21. Nachemson AL. Disc pressure measurements. Spine 1981;6:93-7.

22. Battie MC, Videman T, Gibbons LE, et al. Occupational driving and lumbar disc degeneration: a case-control study. Lancet 2002;360:1369-74.

23. Battie MC, Videman T, Gibbons LE, et al. 1995 Volvo Award in clinical sciences. Determinants of lumbar disc degeneration. A study relating lifetime exposures and magnetic resonance imaging findings in identical twins. Spine 1995;20:2601-12.

24. Borenstein DG, O'Mara JW, Jr., Boden SD, et al. The value of magnetic resonance imaging of the lumbar spine to predict low-back pain in asymptomatic subjects: a seven-year follow-up study. J Bone Joint Surg Am 2001; 83-A:1306-11.

25. Videman T, Battie MC, Gibbons LE, et al. Associations between back pain history and lumbar MRI findings. Spine 2003;28:582-8.

26. Wiesel SW, Tsourmas N, Feffer HL, et al. A study of computer-assisted tomography. I. The incidence of positive CAT scans in an asymptomatic group of patients. Spine 1984;9:549-51.

27. Dvorak J, Panjabi MM, Novotny JE, et al. Clinical validation of functional flexion-extension roentgenograms of the lumbar spine. Spine 1991; 16:943-50.

28. Jayaraman G, Nazre AA, McCann V, et al. A computerized technique for analyzing lateral bending behavior of subjects with normal and impaired lumbar spine. A pilot study. Spine 1994;19:824-32.

29. Kaigle AM, Wessberg P, Hansson TH. Muscular and kinematic behavior of the lumbar spine during flexion-extension. J Spinal Disord 1998;11:163-74.

30. Lund T, Nydegger T, Schlenzka D, et al. Three-dimensional motion patterns during active bending in patients with chronic low back pain. Spine 2002;27:1865-74.

31. Pearcy M, Portek I, Shepherd J. The effect of low-back pain on lumbar spinal movements measured by three-dimensional x-ray analysis. Spine 1985;10:150-3.

32. Chen WJ, Chiou WK, Lee YH, et al. Myo-electric behavior of the trunk muscles during static load holding in healthy subjects and low back pain patients. Clin Biomech (Bristol, Avon) 1998;13:S9-S15.

33. Hubley-Kozey CL, Vezina MJ. Differentiating temporal electromyographic waveforms between those with chronic low back pain and healthy controls. Clin Biomech (Bristol, Avon) 2002;17:621-9.

34. Lariviere C, Gagnon D, Loisel P. A biomechanical comparison of lifting techniques between subjects with and without chronic low back pain during freestyle lifting and lowering tasks. Clin Biomech (Bristol, Avon) 2002;17: 89-98.

35. Marras WS, Davis KG, Ferguson SA, et al. Spine loading characteristics of patients with low back pain compared with asymptomatic individuals. Spine 2001;26:2566-74.

36. Gardner-Morse MG, Stokes IA. The effects of abdominal muscle coactivation on lumbar spine stability. Spine 1998;23:86-91; discussion 92.

37. Lavender SA, Tsuang YH, Andersson GB, et al. Trunk muscle cocontraction: the effects of moment direction and moment magnitude. J Orthop Res 1992;10:691-700.

38. McGill S, Seguin J, Bennett G. Passive stiffness of the lumbar torso in flexion, extension, lateral bending, and axial rotation. Effect of belt wearing and breath holding. Spine 1994;19:696-704.

39. Gardner-Morse MG, Stokes IA. Physiological axial compressive preloads increase motion segment stiffness, linearity and hysteresis in all six degrees of freedom for small displacements about the neutral posture. J Orthop Res 2003;21:547-52.

40. Kaigle A, Ekstrom L, Holm S, et al. In vivo dynamic stiffness of the porcine lumbar spine exposed to cyclic loading: influence of load and degeneration. J Spinal Disord 1998;11:65-70.

41. Patwardhan AG, Havey RM, Carandang G, et al. Effect of compressive follower preload on the flexion-extension response of the human lumbar spine. J Orthop Res 2003;21:540-6.

42. Rohlmann A, Neller S, Claes L, et al. Influence of a follower load on intradiscal pressure and intersegmental rotation of the lumbar spine. Spine 2001;26:E557-61.

43. Stokes IA, Gardner-Morse M. Spinal stiffness increases with axial load: 
another stabilizing consequence of muscle action. J Electromyogr Kinesiol 2003; $13: 397-402$

44. van Dieen JH, Selen LP, Cholewicki J. Trunk muscle activation in low-back pain patients, an analysis of the literature. J Electromyogr Kinesiol 2003; 13:333-51.

45. Ashton-Miller JA, Schultz AB. Spine instability and segmental hypermobility biomechanics: A call for the definition and standard use of terms. Sem Spine Surg 1991;3:136-48.

46. Mimura M, Panjabi MM, Oxland TR, et al. Disc degeneration affects the multidirectional flexibility of the lumbar spine. Spine 1994;19:1371-80.

47. Fujiwara A, Lim TH, An HS, et al. The effect of disc degeneration and facet joint osteoarthritis on the segmental flexibility of the lumbar spine. Spine 2000;25:3036-44.

48. Nachemson AL, Schultz AB, Berkson MH. Mechanical properties of human lumbar spine motion segments. Influence of age, sex, disc level, and degeneration. Spine 1979;4:1-8.

49. Panjabi MM. The stabilizing system of the spine. Part II. Neutral zone and instability hypothesis. J Spinal Disord 1992;5:390-6; discussion 397.

50. Lowery WD, Jr., Horn TJ, Boden SD, et al. Impairment evaluation based on spinal range of motion in normal subjects. J Spinal Disord 1992;5:398402.

51. Battie MC, Bigos SJ, Fisher LD, et al. The role of spinal flexibility in back pain complaints within industry. A prospective study. Spine 1990;15:768-73.

52. Antoniou J, Steffen T, Nelson F, et al. The human lumbar intervertebral disc: evidence for changes in the biosynthesis and denaturation of the extracellular matrix with growth, maturation, ageing, and degeneration. J Clin Invest 1996;98:996-1003.

53. Buckwalter JA. Aging and degeneration of the human intervertebral disc. Spine 1995;20:1307-14.

54. Lyons G, Eisenstein SM, Sweet MB. Biochemical changes in intervertebral disc degeneration. Biochim Biophys Acta 1981;673:443-53.

55. Miller JA, Schmatz C, Schultz AB. Lumbar disc degeneration: correlation with age, sex, and spine level in 600 autopsy specimens. Spine 1988;13: 173-8.

56. Pearce RH, Grimmer BJ, Adams ME. Degeneration and the chemical composition of the human lumbar intervertebral disc. J Orthop Res 1987;5: 198-205.

57. Cassidy JJ, Hiltner A, Baer E. Hierarchical structure of the intervertebral disc. Connect Tissue Res 1989;23:75-88.

58. Marchand F, Ahmed AM. Investigation of the laminate structure of lumbar disc anulus fibrosus. Spine 1990;15:402-10.

59. Tsuji $\mathrm{H}$, Hirano N, Ohshima H, et al. Structural variation of the anterior and posterior anulus fibrosus in the development of human lumbar intervertebral disc. A risk factor for intervertebral disc rupture. Spine 1993;18: 204-10.

60. Iatridis JC, Setton LA, Weidenbaum M, et al. Alterations in the mechanical behavior of the human lumbar nucleus pulposus with degeneration and aging. J Orthop Res 1997;15:318-22.

61. Iatridis JC, Setton LA, Foster RJ, et al. Degeneration affects the anisotropic and nonlinear behaviors of human anulus fibrosus in compression. J Biomech 1998;31:535-44.

62. Gu WY, Mao XG, Foster RJ, et al. The anisotropic hydraulic permeability of human lumbar anulus fibrosus. Influence of age, degeneration, direction, and water content. Spine 1999;24:2449-55.

63. Iatridis JC, Kumar S, Foster RJ, et al. Shear mechanical properties of human lumbar annulus fibrosus. J Orthop Res 1999;17:732-7.

64. Acaroglu ER, Iatridis JC, Setton LA, et al. Degeneration and aging affect the tensile behavior of human lumbar anulus fibrosus. Spine 1995;20:2690701.

65. Gu WY, Mao XG, Rawlins BA, et al. Streaming potential of human lumbar anulus fibrosus is anisotropic and affected by disc degeneration. J Biomech 1999;32:1177-82.

66. Adams MA, McNally DS, Dolan P. "Stress" distributions inside intervertebral discs. The effects of age and degeneration. J Bone Joint Surg Br 1996;78:965-72.

67. Panjabi M, Brown M, Lindahl S, et al. Intrinsic disc pressure as a measure of integrity of the lumbar spine. Spine 1988;13:913-7.

68. Sato K, Kikuchi S, Yonezawa T. In vivo intradiscal pressure measurement in healthy individuals and in patients with ongoing back problems. Spine 1999;24:2468-74.

69. Adams MA, McMillan DW, Green TP, et al. Sustained loading generates stress concentrations in lumbar intervertebral discs. Spine 1996;21:434-8.

70. Dunlop RB, Adams MA, Hutton WC. Disc space narrowing and the lumbar facet joints. J Bone Joint Surg Br 1984;66:706-10.

71. Adams MA, Hutton WC. The relevance of torsion to the mechanical derangement of the lumbar spine. Spine 1981;6:241-8.
72. Adams MA, Hutton WC. Prolapsed intervertebral disc. A hyperflexion injury. 1981 Volvo Award in Basic Science. Spine 1982;7:184-91.

73. Callaghan JP, McGill SM. Intervertebral disc herniation: studies on a porcine model exposed to highly repetitive flexion/extension motion with compressive force. Clin Biomech (Bristol, Avon) 2001;16:28-37.

74. Iatridis JC, ap Gwynn I. Mechanisms for mechanical damage in the intervertebral disc annulus fibrosus. J Biomechanics 2004;37:1165-75.

75. Iatridis JC, MacLean JJ, Ryan DA. Mechanical damage to the intervertebral disc annulus fibrosus subjected to tensile loading. J Biomechanics 2004. In press.

76. Meakin JR, Hukins DW. Effect of removing the nucleus pulposus on the deformation of the annulus fibrosus during compression of the intervertebral disc. J Biomech 2000;33:575-80.

77. Seroussi RE, Krag MH, Muller DL, et al. Internal deformations of intact and denucleated human lumbar discs subjected to compression, flexion, and extension loads. J Orthop Res 1989;7:122-31.

78. Goel VK, Monroe BT, Gilbertson LG, et al. Interlaminar shear stresses and laminae separation in a disc. Finite element analysis of the L3-L4 motion segment subjected to axial compressive loads. Spine 1995;20:689-98.

79. Haughton VM, Schmidt TA, Keele K, et al. Flexibility of lumbar spinal motion segments correlated to type of tears in the annulus fibrosus. J Neurosurg 2000;92:81-6.

80. Osti OL, Vernon-Roberts B, Moore R, et al. Annular tears and disc degeneration in the lumbar spine. A post-mortem study of 135 discs. J Bone Joint Surg Br 1992;74:678-82.

81. Natarajan RN, Ke JH, Andersson GB. A model to study the disc degeneration process. Spine 1994;19:259-65.

82. McKenzie R, Donelson R. Mechanical diagnosis and therapy for low back pain. Toward a better understanding. In: Weisel SW, Weinstein JN, Herkowitz H, et al. eds. The Lumbar Spine. 2nd ed. Philadelphia, PA: W. B. Saunders; 1996;998-1011.

83. Pope MH, Magnusson M, Wilder DG. Kappa Delta Award. Low back pain and whole body vibration. Clin Orthop 1998;241-8.

84. Chow DH, Luk KD, Evans JH, et al. Effects of short anterior lumbar interbody fusion on biomechanics of neighboring unfused segments. Spine 1996; 21:549-55.

85. Dekutoski MB, Schendel MJ, Ogilvie JW, et al. Comparison of in vivo and in vitro adjacent segment motion after lumbar fusion. Spine 1994;19: $1745-51$

86. Goel VK, Lim TH, Gwon J, et al. Effects of rigidity of an internal fixation device. A comprehensive biomechanical investigation. Spine 1991;16: S155-61.

87. Ha KY, Schendel MJ, Lewis JL, et al. Effect of immobilization and configuration on lumbar adjacent-segment biomechanics. J Spinal Disord 1993; 6:99-105.

88. Kim YE, Goel VK, Weinstein JN, et al. Effect of disc degeneration at one level on the adjacent level in axial mode. Spine 1991;16:331-5.

89. Lee CK, Langrana NA. Lumbosacral spinal fusion. A biomechanical study. Spine 1984;9:574-81.

90. Nagata H, Schendel MJ, Transfeldt EE, et al. The effects of immobilization of long segments of the spine on the adjacent and distal facet force and lumbosacral motion. Spine 1993;18:2471-9.

91. Weinhoffer SL, Guyer RD, Herbert M, et al. Intradiscal pressure measurements above an instrumented fusion. A cadaveric study. Spine 1995;20: $526-31$

92. Cole TC, Burkhardt D, Ghosh P, et al. Effects of spinal fusion on the proteoglycans of the canine intervertebral disc. J Orthop Res 1985;3:277-91.

93. Frymoyer JW, Hanley EN, Jr., Howe J, et al. A comparison of radiographic findings in fusion and nonfusion patients ten or more years following lumbar disc surgery. Spine 1979;4:435-40.

94. Kumar MN, Jacquot F, Hall H. Long-term follow-up of functional outcomes and radiographic changes at adjacent levels following lumbar spine fusion for degenerative disc disease. Eur Spine J 2001;10:309-13.

95. Throckmorton TW, Hilibrand AS, Mencio GA, et al. The impact of adjacent level disc degeneration on health status outcomes following lumbar fusion. Spine 2003;28:2546-50.

96. Whitecloud TS, 3rd, Davis JM, Olive PM. Operative treatment of the degenerated segment adjacent to a lumbar fusion. Spine 1994;19:531-6.

97. Penta M, Sandhu A, Fraser RD. Magnetic resonance imaging assessment of disc degeneration 10 years after anterior lumbar interbody fusion. Spine 1995;20:743-7.

98. Penta M, Fraser RD. Anterior lumbar interbody fusion. A minimum 10year follow-up. Spine 1997;22:2429-34.

99. Brickley-Parsons D, Glimcher MJ. Is the chemistry of collagen in intervertebral discs an expression of Wolff's Law? A study of the human lumbar spine. Spine 1984;9:148-63.

100. Antoniou J, Arlet V, Goswami T, et al. Elevated synthetic activity in the 
convex side of scoliotic intervertebral discs and endplates compared with normal tissues. Spine 2001;26:E198-206.

101. Boos N, Nerlich AG, Wiest I, et al. Immunolocalization of type X collagen in human lumbar intervertebral discs during ageing and degeneration. Histochem Cell Biol 1997;108:471-80.

102. Melrose J, Gurr KR, Cole TC, et al. The influence of scoliosis and ageing on proteoglycan heterogeneity in the human intervertebral disc. J Orthop Res 1991;9:68-77.

103. Oegema TR, Jr., Bradford DS, Cooper KM, et al. Comparison of the biochemistry of proteoglycans isolated from normal, idiopathic scoliotic and cerebral palsy spines. Spine 1983;8:378-84.

104. Wu JJ, Eyre DR, Slayter HS. Type VI collagen of the intervertebral disc. Biochemical and electron-microscopic characterization of the native protein. Biochem J 1987;248:373-81.

105. Bibby SR, Fairbank JC, Urban MR, et al. Cell viability in scoliotic discs in relation to disc deformity and nutrient levels. Spine 2002;27:2220-8; discussion 2227-8.

106. Urban MR, Fairbank JC, Etherington PJ, et al. Electrochemical measurement of transport into scoliotic intervertebral discs in vivo using nitrous oxide as a tracer. Spine 2001;26:984-90.

107. Krag M. Animal models for human disk degeneration. In: Weinstein JM, Gordon SL, eds. Low Back Pain: A Scientific and Clinical Overview. Rosemont, IL: American Academy of Orthopaedic Surgeons; 1996;479-92.

108. Puustjarvi K, Lammi M, Kiviranta I, et al. Proteoglycan synthesis in canine intervertebral discs after long-distance running training. J Orthop Res 1993;11:738-46.

109. Hutton WC, Toribatake Y, Elmer WA, et al. The effect of compressive force applied to the intervertebral disc in vivo. A study of proteoglycans and collagen. Spine 1998;23:2524-37.

110. Hutton WC, Ganey TM, Elmer WA, et al. Does long-term compressive loading on the intervertebral disc cause degeneration? Spine 2000;25: 2993-3004.

111. Lipson SJ, Muir H. 1980 Volvo award in basic science. Proteoglycans in experimental intervertebral disc degeneration. Spine 1981;6:194-210.

112. Osti OL, Vernon-Roberts B, Fraser RD. 1990 Volvo Award in experimental studies. Anulus tears and intervertebral disc degeneration. An experimental study using an animal model. Spine 1990;15:762-7.

113. Sullivan JD, Farfan HF, Kahn DS. Pathologic changes with intervertebral joint rotational instability in the rabbit. Can J Surg 1971;14:71-9.

114. Stokes IA, Counts DF, Frymoyer JW. Experimental instability in the rabbit lumbar spine. Spine 1989;14:68-72.

115. Hsieh AH, Lotz JC. Prolonged spinal loading induces matrix metalloproteinase-2 activation in intervertebral discs. Spine 2003;28:1781-8.

116. Iatridis JC, Mente PL, Stokes IA, et al. Compression-induced changes in intervertebral disc properties in a rat tail model. Spine 1999;24:996-1002.

117. Lotz JC, Chin JR. Intervertebral disc cell death is dependent on the magnitude and duration of spinal loading. Spine 2000;25:1477-83.
118. Lotz JC, Colliou OK, Chin JR, et al. Compression-induced degeneration of the intervertebral disc: an in vivo mouse model and finite-element study. Spine 1998;23:2493-506.

119. Palmer EI, Lotz JC. The compressive creep properties of normal and degenerated murine intervertebral discs. J Orthop Res 2004;22:164-9.

120. Elliott DM, Sarver JJ. Young investigator award winner: validation of the mouse and rat disc as mechanical models of the human lumbar disc. Spine 2004:29:713-22.

121. MacLean JJ, Lee CR, Grad S, et al. Effects of immobilization and dynamic compression on intervertebral disc cell gene expression in vivo. Spine 2003; 28:973-81.

122. Walsh AJ, Lotz JC. Biological response of the intervertebral disc to dynamic loading. J Biomech 2004;37:329-37.

123. MacLean JJ, Lee CR, Alini M, et al. Anabolic and catabolic mRNA levels of the intervertebral disc vary with the magnitude and frequency of in vivo dynamic compression. J Orthop Res 2004;22:1193-200.

124. Ching CT, Chow DH, Yao FY, et al. The effect of cyclic compression on the mechanical properties of the inter-vertebral disc: an in vivo study in a rat tail model. Clin Biomech (Bristol, Avon) 2003;18:182-9.

125. Urban JP, Holm S, Maroudas A, et al. Nutrition of the intervertebral disc: effect of fluid flow on solute transport. Clin Orthop 1982;296-302.

126. Urban JP, McMullin JF. Swelling pressure of the lumbar intervertebral discs: influence of age, spinal level, composition, and degeneration. Spine 1988;13:179-87.

127. Chen J, Baer AE, Paik PY, et al. Matrix protein gene expression in intervertebral disc cells subjected to altered osmolarity. Biochem Biophys Res Commun 2002;293:932-8.

128. Handa $\mathrm{T}$, Ishihara $\mathrm{H}$, Ohshima $\mathrm{H}$, et al. Effects of hydrostatic pressure on matrix synthesis and matrix metalloproteinase production in the human lumbar intervertebral disc. Spine 1997;22:1085-91.

129. Hutton WC, Elmer WA, Boden SD, et al. The effect of hydrostatic pressure on intervertebral disc metabolism. Spine 1999;24:1507-15.

130. Hutton WC, Elmer WA, Bryce LM, et al. Do the intervertebral disc cells respond to different levels of hydrostatic pressure? Clin Biomech (Bristol, Avon) 2001;16:728-34.

131. Ishihara H, McNally DS, Urban JP, et al. Effects of hydrostatic pressure on matrix synthesis in different regions of the intervertebral disc. J Appl Physiol 1996;80:839-46.

132. Ohshima H, Urban JP, Bergel DH. Effect of static load on matrix synthesis rates in the intervertebral disc measured in vitro by a new perfusion technique. J Orthop Res 1995;13:22-9.

133. Hirano N, Tsuji H, Ohshima H, et al. Analysis of rabbit intervertebral disc physiology based on water metabolism. I. Factors influencing metabolism of the normal intervertebral discs. Spine 1988;13:1291-6.

134. Baer AE, Laursen TA, Guilak F, et al. The micromechanical environment of intervertebral disc cells determined by a finite deformation, anisotropic, and biphasic finite element model. J Biomech Eng 2003;125:1-11. 